\title{
Examining the effectiveness of training assertiveness skill on self- efficacy and procrastination of the female seventh grade junior students, District 19, Tehran: the educational year of 2014-2015
}

\author{
Marzeyeh Moradi \\ MA, Department of Psychology, Central Tehran Branch, Islamic Azad University, Tehran, IRAN \\ E-mail address: Minasmoradi@yahoo.com
}

Keywords: Assertiveness skill, Self-efficacy, Procrastination.

\begin{abstract}
Its salient example is to procrastinate in studying lessons until the night of examination and haste and anxiety resulting from it that has entangled students. The prevalence of educational procrastination among students justifies the necessity of the attention by officials, planners and practitioners of the educational system to the variables related with it like educational self-efficacy and training assertiveness skills; because educational procrastination on the one hand, indicates low educational self-efficacy and on the other hand, is an incompatible and ineffective defense strategy including the problem in establishing collective communication and lacking necessary social skills where the learners utilize it for avoiding defeat, maintaining self-respect and personal value, thus entailing non-compensable repercussions for the procrastinator . The current research has been conducted with the aim of determining the effectiveness of training assertiveness skill on self-efficacy and procrastination of the female seventh grade junior students. The statistical population of this research included 30 students who were selected through available sampling method while they were randomly assigned in the group. The research tools in addition to the Personal Characteristics Inventory consisted of three Ratos assertiveness inventory (PRAS), Scherer self- efficacy (SGSES) and Procrastination Inventory by Tuckman (1991). To analyze the data the Covariance analysis was applied. Results indicated that there was not a significant relationship between training effectiveness of assertiveness skill on self- efficacy and procrastination.
\end{abstract}

\section{INTRODUCTION}

Adolescence is one of the critic periods of life during which people have communicational issues and attempt to form their identity and perceive their own surrounding differently (Koparan et al, 2009). Adolscents find their way into the peer groups and form their own social life basis through acquiring social skills like collaboration, compromise, communication and making friends. Of major problems leaving deterrent effect on efficacy of adolscents and avoid the healthy formation of their identity, prosperity of talents and emotional and intellectual power is the problem of lacking a collective communication and forfeiting necessary social skills (Mehrabi Zade Honarmand et 1, 2010). Children who have acquired social skills are more successful than the children lacking such skills in creating communications with their peers and in learning in educational settings (Asher and Taylor, 2001). The condition for establishing good social skills is also the ability for assertiveness. Assertiveness is the skills of establishing interpersonal skills (Albert and Emons, 1982), and center for interpersonal behavior and human relations (Lin et al, 2004). In fact, that which adds to the significance of training assertiveness skills is that at a personal level it leads to promotion of personal capabilities and increase of social-mental capacity of people and at a social level, this will cause them to be responsible, active and selective.

For this, training assertiveness skill could ne influential in the educational success of the adolscents. Self- efficacy has been for years hovering in the focal point of the developmental psychologists and other educational experts. Bandura (1993) is among the social-cognitive theorists who has investigated effective mechanisms; mechanisms which have fundamental roles in doing assignments. Among the influential mechanisms, he considers none in controlling functions as more 
influential than self-efficacy and peoples' beliefs of ability (Pajares and Miller, 1997). On the other hand, he maintains that self-efficacy, like a motivational -cognitive factor has a valuable role in emergence of personal and gender differences in a range of educational functions (Bandura, 1993). Bandura defines self-efficacy as person's judgment and perception regarding his own abilities and skills for doing things to which he needs on special conditions. On the other hand, self-efficacy is only effective on functions when the person possesses necessary skills for doing special work and is motivated to a higher extent for doing so Pajares and Miller, 1997). Understating predicting variables of educational procrastination on the one hand will increase the prevention of failure outcomes at school and thus contributes to reliance on applied priorities. Within the framework of the self-efficacy, it has been stated that people with strong beliefs have doubts have better competency compared to people who have doubts in doing things and thus they prove be self0effectie in what they do (Bandura, 1993). In other words, Bandura argues that people who have less confidence on successfully doing their homework are highly likely to avoid the assignments instead of getting entangled with it. Therefore, people who report lower self-efficacy are more inclined to procrastination and delay their work while people with higher self- efficacy are less likely to tend to procrastination. In addition to this, self-efficacy is thought to be an effective variable on educational procrastinations since it demonstrates its impacts through struggle and insistence in doing assignments (Schunk, 1996).Among problem student are facing with is procrastination in doing their homework. It is been for thousands of years that procrastination as meaning delaying the work of today to tomorrow has created problems. The common form of learners' procrastination is procrastination at the beginning of homework and then thee student is obliged to intensively work so that they do their homework on some special occasions.

In educational procrastination, the procrastination conduct is performed in such educational; activities as getting present for examination. Doing home homework an writing papers (Beck et al, 2002). Non-educational procrastination relates to other life situations such as paying the bills, washing dishes, answer the phone and the like (Milgram et al, 1998). Upon the researches by Milgram et al (1998) there is a significant relationship between educational procrastination and noneducational procrastination (0/65). For Lin et al, (2004) most students with procrastination are uncomfortable in all aspects of life in addition to having problems in study programs or inability to acquire higher marks. Th term procrastination is equivalent to negligence and postponement of works. Procrastination or postponement to the future is so common that it could be considered to be of human inherent tendencies. Although procrastination is not always problematic, it entails unfavorable and irreparable consequences through hindrance from progress and lack of access to objectives (Ellis and Knaus, 1997). Procrastination or postponement has various manifestations in accordance with complexities of cognitive, emotional and behavioral components, including educational procrastination which is defined as the prevalent tendency of learners for delaying educational activities which are always accompanied by anxiety. Psychologically speaking, procrastination means postponing affairs to the future for which we have adopted decisions; it is unfavorable and indecent behavior which turns into a habit in the human being gradually (Khosrawi, 2010). Procrastination is considered to be a habit which prevails in different societies and it is growing increasingly. This habit is accompanied with delay in doing affairs or responsibly and as a consequence it entails unfavorable repercussions. Although it is possible the negative consequences of this habit cannot be definite and clear in the daily life, the losses arising from the prevalence of this behavior among different groups of people are considerable and this same issue reveals then necessity of avoiding such a behavior (Ali Madadi, 2010). The current research has been conducted with the aim of determining the effectiveness of training assertiveness skill on selfefficacy and procrastination of the high school students. 


\section{METHODOLOGY}

The outline chosen for this research is the pretest-posttest with the control group. The statistical population of this research included 30 seventh grade students in the educational yar of 2014-2015 who were selected through available sampling method while the current research sample contains 15 seventh grade students for each group.

\section{Research tools}

The research tools in addition to the Personal Characteristics Inventory consisted of three Ratos assertiveness inventory (PRAS), Scherer self- efficacy (SGSES) and Procrastination Inventory by Tuckman (1991).

Ratos assertiveness inventory (PRAS): This inventory was developed in 1984 by McCormick in order to assess the assertiveness of people who were thought to be weak in the reading skill.

Scoring method: Very much like to me: 6; almost like to me: 5; partly like to me: 4; partly unlike me:3 ; almost unlike me: 2 ; very much like me: 1 .

In phrases of 1-2-4-5-9-11-12-13-14-15-16-17-19-23-24-26-30 scoring is done inversely. The total score is obtained from the aggregate of all the 30 phrases. The scores ranges between 30 and 180 and higher scores suggest more assertiveness.

Credibility and validity: the Ratos assertiveness inventory (PRAS) has been administered for standardization of a sample containing 116 graduate students. The average and SD scores among women were 94/6 and 25/4 (n:82) and in men 99/8 and 02/1 (n: 34) respectively. The internal constancy of t6his scale was tested by means of correlation assessment of pair and single phrases and its value was reported to be $0 / 90$.

Scherer self- efficacy (SGSES): this form contains 17 phrases. This scale measures three aspects of behavior including tendency to start behavior, tendency to expanding efforts for completing assignment and being different in facing with obstacles.

Scoring method: The general self-efficacy inventory is as follows: each item is given a score of 1 to 5 (totally disgraee: 1 to totally agree: 5). Generally, this questionnaire contains 17 items where the items numbered 3 and 8 and 9 and 13 and 15 are from left to right while the rest from right to left get their scores increased and higher scores indicate more and higher self-efficacy.

Credibility and validity: The internal constancy of the whole Cronbach's alpha coefficient scale relating to the whole of the test phrases and each off the phrases (factors) was estimated. Given the results, the first factor has the highest average and disparity while the third factors have the least average and disparity. The Cronbach's alpha coefficient of the whole scale and the alpha coefficients of each factor were estimated. In this estimate, the first factors having the greatest items assume a higher coefficient compared to other factors while the third factor has smaller items and fewer coefficients.

Procrastination Inventory by Tuckman (1991): Procrastination in Latin language consists of two parts of pro meaning (forwards) and (in support of) and crastius meaning (tomorrow) and literally means until tomorrow. Its synonyms are cunctation, Shilly- shally and dilatoriness and delaying things due to habits in inattention and laziness and postponement or some unnecessary delay (Ellis and Knaus, 2002; translated by Nik Azin, 2013). This phenomenon involves two cognitive and behavioral levels. At the behavioral level, the individual does not do the affair he had intended to do without any social reasons and on purpose and the cognitive level the individual delays in making timely decisions. 
Scoring methods: This inventory contains 16 four choice phrases:

Fully sure: 1; partly sure: 2; partly not sure: 3 ; fully not sure: 4

After scoring choices from an aggregate of questions scores, the total score is estimated. The range of scores varies between 16 and 64. The lower score means more tendencies to procrastination. Questions 7, 12, 14 and 16 are inversely scored. The average scores for students is /40 (Tuckman, 1991; quoted by Moghadas Bayat, 2005).

Credibility and validity: The questionnaire's alpha coefficient is 0/90 which indicates an acceptable reliability of the instrument. Tuckman (1991) obtained a six question single factor form via the internal constancy of 0/86. In the research by Stober and Joorman (2001), the Cronbach's alpha level of this questionnaire was obtained to be 0/92 for sample of 185 students. Also, the correlation of this instrument with the Pennsylvania anxiety and depression inventories (PSWQ) was obtained to be $0 / 32,0 / 30$ and $0 / 32$ respectively. The reliability of the said questionnaire by Moghadas Bayat (2005) was acquired to be $0 / 73$ indicating acceptable reliability.

\section{RESEARCH IMPLEMENTATION METHOD}

After coordination with the officials of the Education department, Hijab school in district 19 was referred. Questionnaires were collectively provided to the students with infinite time. Thereafter students were randomly divided into two experimental and control groups. In the next stage, the educational program of assertiveness (eight sessions of 45 minutes each like the following) was administered to the experimental group. After the end of the educational intervention, questionnaires were once again distributed to the two groups.

\section{Educational program}

In this educational program, the role playing method was used. Role playing is a method in which the therapist demands the client to conduct the behavior intended in an artificial situation similar to the actual situation of life; in this situation the client and therapist engage in an interpersonal, interaction related with the client. The number of sessions for assertiveness training was considered to be eight sessions of 45 minutes each during four weeks. In each of the sessions and in accordance with the titles presented later, the students will be engaged in exchange of views and explanation about the content of that session as well as examples regarding the skills and some practical examples. In other words, the student with the instructor gets into role plays the skills. In the end of each session, some exercises are considered for work at home.

\section{Session programs}

First and second session: Expressing the introduction, defining assertiveness a $\mathrm{d}$ necessity and benefits of it in life, types of behaviors and behavioral and verbal characteristics

Third session: Training how to reject irrational request and saying no and their reasons, difficulties in stating no and how to say no

Fourth session: Training the skill of saying no, reasons for the difficulty and how to say yes

Fifth session: Training the skill of requesting and reasons for requesting and its consequences

Sixth session: Training the skill of expressing negative and positive feelings (anger and happiness) and the reasons impeding expression of feelings

Seventh session: Training the skill of constructive criticism, constructive criticism reasons, how to deal with constructive criticism and hot to criticize

Eighth session: Conclusion and reviewing contents and removing ambiguities 


\section{FINDINGS}

In this research, we first address subscales of the three variables under investigation and later we deal with covariance test. In table 1, three variables of assertiveness, self-efficacy and procrastination in the control group are displayed in two pretest and posttest stages through bar graphs.

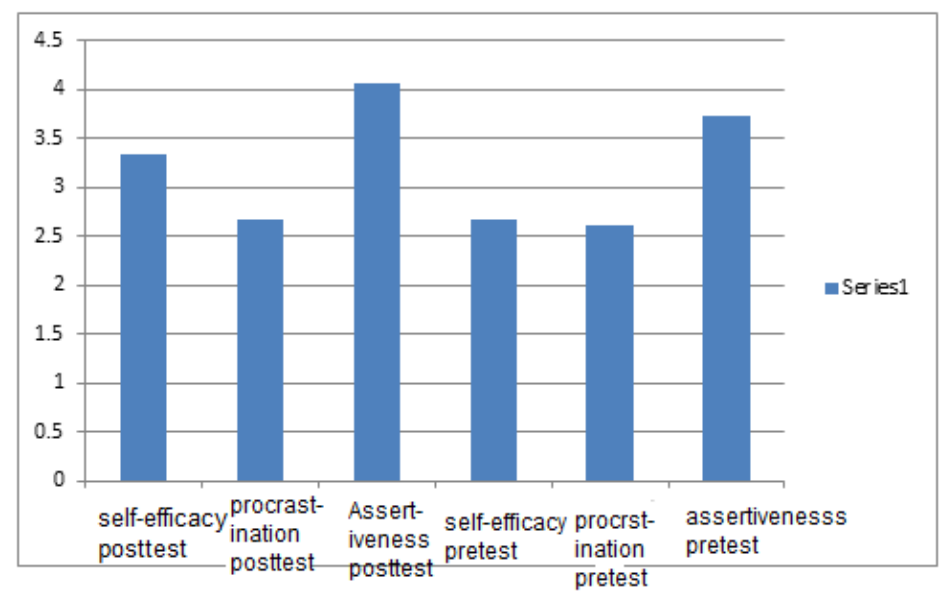

Graph 1: Three variables of assertiveness, self-efficacy and procrastination in the control group

In table 2, three variables of assertiveness, self-efficacy and procrastination in the control group are displayed in two pretest and posttest stages through bar graphs.

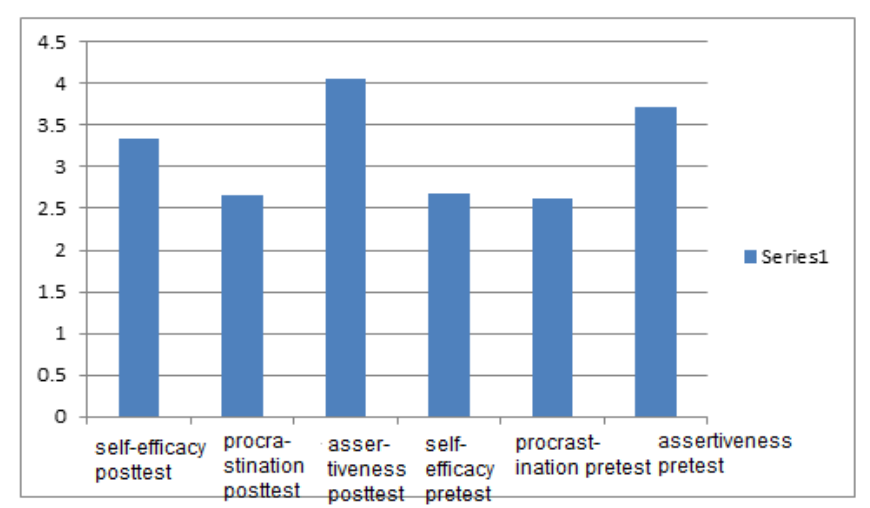

Graph 2: Three variables of assertiveness, self-efficacy and procrastination in the experimental group

The above graph indicates that in then experimental group, the average of variables of assertiveness and self-efficacy in the posttest stage is greater than in the pretest. Since, this result is also obtained in the control group, one cannot certainly conclude from the effectiveness of the education. Later, in inferential statistics, these instances are investigated by means of covariance test.

Table 1: Descriptive statistics indices ( $\mathrm{A}=$ assertiveness; $\mathrm{P}=$ procrastination; $\mathrm{S}=$ self-efficacy).

\begin{tabular}{|c|c|c|c|c|c|c|c|c|c|c|c|}
\hline \multirow{2}{*}{\multicolumn{3}{|c|}{ Variable }} & \multirow{2}{*}{\multicolumn{3}{|c|}{ Distribution indices }} & \multirow{2}{*}{\multicolumn{3}{|c|}{ Disparity indices }} & \multirow{2}{*}{\multicolumn{3}{|c|}{ Central indices }} \\
\hline & & & & & & & & & & & \\
\hline \multirow{6}{*}{$\begin{array}{l}\text { Control } \\
\text { group }\end{array}$} & \multirow{3}{*}{ Pretest } & $\bar{A}$ & $1 / 98$ & $0 / 35$ & $0 / 16$ & $0 / 59$ & $0 / 35$ & $2 / 37$ & $3 / 77$ & $3 / 80$ & $3 / 33$ \\
\hline & & $\mathrm{P}$ & $0 / 19$ & $0 / 22$ & $0 / 13$ & $0 / 47$ & $0 / 22$ & $1 / 69$ & $2 / 83$ & $2 / 87$ & $2 / 75$ \\
\hline & & S & $-1 / 22$ & $0 / 39$ & $0 / 19$ & $0 / 62$ & $0 / 39$ & $1 / 76$ & $2 / 64$ & $2 / 47$ & $1 / 82$ \\
\hline & \multirow[t]{3}{*}{ Posttest } & $\mathrm{A}$ & $0 / 14$ & $0 / 28$ & $0 / 16$ & $0 / 53$ & $0 / 28$ & $1 / 77$ & $3 / 60$ & $3 / 73$ & $3 / 93$ \\
\hline & & $\mathrm{P}$ & $0 / 04$ & $-0 / 25$ & $0 / 14$ & $0 / 55$ & $0 / 30$ & 2 & $2 / 58$ & $2 / 53$ & $2 / 50$ \\
\hline & & $\mathrm{S}$ & $-0 / 59$ & $0 / 19$ & $0 / 14$ & $0 / 56$ & $0 / 32$ & 2 & $3 / 10$ & $3 / 05$ & $2 / 49$ \\
\hline \multirow{6}{*}{$\begin{array}{l}\text { Experi } \\
\text { mental } \\
\text { group }\end{array}$} & \multirow[t]{3}{*}{ Pretest } & $\mathrm{A}$ & $-0 / 07$ & $0 / 50$ & $0 / 12$ & $0 / 45$ & $0 / 208$ & $1 / 57$ & $3 / 72$ & $3 / 70$ & $3 / 07$ \\
\hline & & $\mathrm{P}$ & $-0 / 019$ & $1 / 08$ & $0 / 11$ & $0 / 44$ & $0 / 195$ & $1 / 44$ & $2 / 62$ & $2 / 43$ & $2 / 38$ \\
\hline & & $\mathrm{S}$ & $0 / 748$ & $1 / 32$ & $0 / 12$ & $0 / 41$ & $0 / 176$ & $1 / 29$ & $2 / 67$ & $2 / 50$ & $2 / 29$ \\
\hline & \multirow[t]{3}{*}{ Posttest } & $\mathrm{A}$ & $1 / 29$ & $0 / 62$ & $0 / 13$ & $0 / 37$ & $0 / 142$ & $1 / 33$ & $4 / 06$ & $4 / 10$ & $4 / 10$ \\
\hline & & $\mathrm{P}$ & $-0 / 19$ & $0 / 85$ & $0 / 085$ & $0 / 30$ & $0 / 096$ & 1 & $2 / 66$ & $2 / 59$ & $2 / 50$ \\
\hline & & $\mathrm{S}$ & $-0 / 78$ & $0 / 013$ & $0 / 15$ & $0 / 48$ & $0 / 231$ & $1 / 53$ & $3 / 53$ & $3 / 29$ & $3 / 29$ \\
\hline
\end{tabular}


In table (1) Statistical indices of the three variables of assertiveness, procrastination and selfefficacy are provide in the two control and experimental groups and in two pretest and posttest stages. Given the values of the central indices which are almost at one level we can conclude that the above data are normally distributed. Also, the low strain and skewed values (2 and -2$)$ of the above finding are confirmed and the first presumption of the covariance analysis is supported.

B) Investigating homogeneity of variance; Leven's Test

Using the Leven's Test, we can examine the homogeneity of variance in the experimental group.

Table 2: Leven's test for investigating the homogeneity of the variance

\begin{tabular}{|l|l|l|l|l|}
\hline & Leven's statistic & $\begin{array}{l}\text { Freedom degree } \\
1\end{array}$ & $\begin{array}{l}\text { Freedom degree } \\
2\end{array}$ & Sig. \\
\hline $\begin{array}{l}\text { Assertiveness } \\
\text { pretest }\end{array}$ & $0 / 155$ & 1 & 28 & $0 / 697$ \\
\hline $\begin{array}{l}\text { Assertiveness } \\
\text { posttest }\end{array}$ & 0 & 1 & 28 & $0 / 993$ \\
\hline $\begin{array}{l}\text { Procrastination } \\
\text { pretest }\end{array}$ & $0 / 177$ & 1 & 28 & $0 / 678$ \\
\hline $\begin{array}{l}\text { Procrastination } \\
\text { posttest }\end{array}$ & $4 / 944$ & 1 & 28 & $0 / 034$ \\
\hline $\begin{array}{l}\text { Self-efficacy } \\
\text { pretest }\end{array}$ & $0 / 274$ & 1 & 28 & $0 / 605$ \\
\hline $\begin{array}{l}\text { Self-efficacy } \\
\text { posttest }\end{array}$ & $0 / 228$ & 1 & 28 & $0 / 637$ \\
\hline
\end{tabular}

If the significance level in the Leven's test is greater than $0 / 05$ we can say that the variance of the groups enjoys homogeneity. In accordance with the values obtained we can conclude that the variance of groups enjoys homogeneity.

Examining the first hypothesis: training assertiveness skill reduces the possibility of procrastination.

Table 3: Interaction between the independent variable and covariate (Dependent variable: procrastination posttest)

\begin{tabular}{|l|l|l|l|l|l|}
\hline $\begin{array}{l}\text { Source of } \\
\text { variations }\end{array}$ & $\begin{array}{l}\text { Sum of } \\
\text { squares }\end{array}$ & $\begin{array}{l}\text { Freedom } \\
\text { degree }\end{array}$ & $\begin{array}{l}\text { Squares } \\
\text { average }\end{array}$ & F value & Sig. \\
\hline $\begin{array}{l}\text { Modified } \\
\text { model }\end{array}$ & $1 / 479$ & 2 & $0 / 739$ & $4 / 992$ & $0 / 014$ \\
\hline intercept & $0 / 779$ & 1 & $0 / 779$ & $5 / 261$ & $0 / 030$ \\
\hline $\begin{array}{l}\text { Procrastination } \\
\text { pretest }\end{array}$ & $1 / 463$ & 1 & $1 / 463$ & $9 / 877$ & $0 / 004$ \\
\hline Group & $0 / 003$ & 1 & $0 / 003$ & $0 / 022$ & $0 / 884$ \\
\hline Error & $3 / 999$ & 27 & $0 / 148$ & & \\
\hline Total & $215 / 160$ & 30 & & & \\
\hline Modified total & $5 / 478$ & 29 & & & \\
\hline
\end{tabular}

According to the $\mathrm{F}$ value $(9 / 877)$ obtained in the procrastination pretest which indicates the effects of the pretest variable (covariate) and the significance level relating to it equals $0 / 004$ or smaller than $0 / 05$ we can say that the correlation of the pretest variable (covariate) and independent variable has been observed, i.e. the variable of pretest and covariate has been correct and this variable has 
had a significant effect on the model recommended. According to the F value $(0 / 022)$ obtained in the independent variable or group and significance relating to it which equals to $0 / 884$ and greater than $0 / 05$ we can say that after removing the effects of the pretest (covariate) no significant differences were observed between the scores of the two groups in posttest. Hence, the research hypothesis, i.e. training assertiveness engenders reduced procrastination is rejected.

Second Hypothesis: Training assertiveness skill will increase self-efficacy.

Table 4: Interaction between the independent variable and covariate (Dependent variable: selfefficacy posttest)

\begin{tabular}{|l|l|l|l|l|l|}
\hline $\begin{array}{l}\text { Source of } \\
\text { variations }\end{array}$ & $\begin{array}{l}\text { Sum of } \\
\text { squares }\end{array}$ & $\begin{array}{l}\text { Freedom } \\
\text { degree }\end{array}$ & $\begin{array}{l}\text { Squares } \\
\text { average }\end{array}$ & F value & Sig. \\
\hline $\begin{array}{l}\text { Modified } \\
\text { model }\end{array}$ & $1 / 658$ & 2 & $0 / 829$ & $3 / 485$ & $0 / 45$ \\
\hline intercept & $2 / 476$ & 1 & $2 / 476$ & $10 / 408$ & $0 / 003$ \\
\hline $\begin{array}{l}\text { Procrastination } \\
\text { pretest }\end{array}$ & $1 / 464$ & 1 & $1 / 464$ & $6 / 155$ & $0 / 020$ \\
\hline Group & $0 / 111$ & 1 & $0 / 111$ & $0 / 467$ & $0 / 50$ \\
\hline Error & $6 / 423$ & 27 & $0 / 238$ & - & - \\
\hline Total & $313 / 401$ & 30 & - & - & - \\
\hline Modified total & $8 / 081$ & 90 & - & - & - \\
\hline
\end{tabular}

According to the F value (6/155) obtained in the self-efficacy pretest which indicates the effects of the pretest variable (covariate) and the significance level relating to it equals $0 / 020$ or smaller than $0 / 05$ we can say that the correlation of the pretest variable (covariate) and independent variable has been observed, i.e. the variable of pretest and covariate has been correct and this variable has had a significant effect on the model recommended. According to the F value $(0 / 467)$ obtained in the independent variable or group and significance relating to it which equals to $0 / 5$ and greater than $0 / 05$ we can say that after removing the effects of the pretest (covariate) no significant differences were observed between the scores of the two groups in posttest. Hence, the research hypothesis, i.e. training assertiveness skill will increase self-efficacy is rejected.

Third hypothesis: Assertiveness skill increase self-efficacy and reduce procrastination

\begin{tabular}{|l|l|l|l|l|l|}
\hline $\begin{array}{l}\text { Source of } \\
\text { variations }\end{array}$ & $\begin{array}{l}\text { Sum of } \\
\text { squares }\end{array}$ & $\begin{array}{l}\text { Freedom } \\
\text { degree }\end{array}$ & $\begin{array}{l}\text { Squares } \\
\text { average }\end{array}$ & F value & Sig. \\
\hline Modified model & $2 / 745$ & 2 & $1 / 372$ & $9 / 184$ & $0 / 001$ \\
\hline intercept & $1 / 58$ & 1 & $1 / 58$ & $10 / 570$ & $0 / 003$ \\
\hline $\begin{array}{l}\text { Procrastination } \\
\text { pretest }\end{array}$ & $2 / 08$ & 1 & $2 / 08$ & $13 / 918$ & $0 / 001$ \\
\hline Group & $0 / 547$ & 1 & $0 / 547$ & $3 / 66$ & $0 / 066$ \\
\hline Error & $4 / 035$ & 27 & $0 / 149$ & - & - \\
\hline Total & $422 / 924$ & 30 & - & - & - \\
\hline Modified total & $6 / 780$ & 29 & - & - & - \\
\hline
\end{tabular}

According to the F value (13/918) obtained in the assertiveness pretest which indicates the effects of the pretest variable (covariate) and the significance level relating to it equals $0 / 001$ or smaller than $0 / 05$ we can say that the correlation of the pretest variable (covariate) and independent variable has been observed, i.e. the variable of pretest and covariate has been correct and this variable has had a significant effect on the model recommended. According to the F value (3/66) obtained in the independent variable or group and significance relating to it which equals to 0/066 and greater than 
0/05 we can say that after removing the effects of the pretest (covariate) no significant differences were observed between the scores of the two groups in posttest. Hence, the research hypothesis, i.e. training assertiveness skill will increase self-efficacy and procrastination is rejected.

\section{CONCLUSION}

The research indicated that three hypotheses were rejected. This research like its predecessors demonstrated that training assertiveness has had no effect on self-efficacy and procrastination of students. According to the theoretical basics of assertiveness and procrastination we cannot state that the effects training assertiveness leaves on other aspects of students are meager. Rather we can claim that we require time to observe effects of assertiveness skill so that the individual can institute in himself assertive behaviors. As stated by many researches in the area of assertiveness, training assertiveness affects various aspects of humans' life. Understanding these instance will contribute to the improvement of life styles among humans (Koparan and et al, 2009).

\section{References}

[1] Alberti, R.\& Emmons.M.(1982).Your perfect right: a guide for assertive living(4 heds). Impact, Luis obisp, California.

[2] Ali Madadi, Z. (2010). Exploring the intermediary role of self-determination in relation between child rearing aspects and educational procrastination of students at the university of Shiraz, M.A. thesis, Faculty of Psychology and Educational sciences, University of Shiraz

[3] Asher, S. \&Taylor.A.(2001) The social outcomes of mainstreaming: socimetric assessment and beyond. Excetional children quarterly,12,12-39.

[4] Bandura, A(1993). Perceived self-efficacy incongnitive Development and functioning Educational psychologist 28(2):117-148.

[5] Beck, B.L.\& Koons, S.R. Migram,D.L.(2002). Correlates and consequencebehavioral procrastination, self-conscioueness, self-csteem, ahd self-handicapping, journal of social behavior and personalitily 15,3-13.

[6] Elis, A, \& Knaus, W.J. (1997). Overcoming procrastination. NewYourk: Irstitutefor Rational Living.

[7] Khosrawi, A. A. (2010). Investigating the relationship between staff's professional satisfaction and their procrastination in the education section of the Iran's Commerce Development Department, Quarterly of leadership and educational management, Islamic Azad University, Garmsar Unit, 3(2): 125-141

[8] Koparan,S. ozturk, F, ozkihc, R(2009). An hnvestingation of social self- efficacy expectation and assertivenss hn multi, program high school students procedial social and Behavioral sciences 1 (2009) 523-629.

[9] Lin,Y.Shiah,S.Chanh,YC.Lai.T.Vang.K,Y.Chou,K.(2004).Evaluati of an assertiveness training programon nursing and medical students assertiveness, self-esteem and interpersonal communication satisfaction. Nurse Education Today. 24,656-665.

[10] Mehrabi Zade Honarmand, M.., Taghavi, F., \& Attari, R. (2010). Effects of assertiveness on social anxiety and educational performance of the female students, 3(1): 111-119.

[11] Milgram,N.A,Mey, Tal,G.,\&Lerinson,Y.(1998).Procrastination, generalized specific, in college student and their personality and Individual Differences, 25,297-316.

[12] Moghadas Bayat, M. (2005). Standardization of the scale for measurement of Tuck man's procrastination scale regarding M.A. students, M.A. thesis, Roudehen Islamic Azad University.

[13]Pajares, F.\& Miler,D.M(1997). Mathematics self- efficacy and mathematical problem solving Implications of using different from of assessment. The journal of experimental education, 65 pp:213-228.

[14]Schunk,H.(1996). Attribution and the Development of self-Regulatory competence. Paper presented at the Annual conference of the American Education Reserch Association, 8- 12 April, Newyork, NY,USA 